\title{
Using PHStat And Camtasia Studio 2 In Teaching Business Statistics
}

\author{
Ranjna Patel, (Email: patelr@cookman.edu), Bethune-Cookman College
}

Carla Feinson, (Email: feinsonc@cookman.edu), Bethune-Cookman College

\begin{abstract}
More and more business professors are integrating technology into their courses to create a more stimulating learning environment and develop better communication channels between students and instructors. Online lessons, whether used as a study aid in the hybrid classroom or, as a complete package for the distance learner, create additional workloads for instructors who are willing to commit to the online environment. Any tool that can ease the creation process is a welcome addition to even the most technologically savvy professor. This paper shows how a statistics application program, such as PHStat, can be fully integrated into a complete online reenactment by using a video/sound capture program such as Camtasia Studio 2.
\end{abstract}

\section{INTRODUCTION}

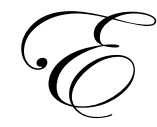

-learning is a productive and timely way to enhance classroom lessons. "It can be significantly cheaper and more productive" than other methods and accounted "for almost half of the projected $\$ 16.9$ billion business skills training market in 2004" (Mayer, 2001).

More and more business professors are integrating technology into their courses to create a more stimulating learning environment and develop better communication channels between students and instructors. Online lessons, whether used as a study aid in the hybrid classroom or, as a complete package for the distance learner, create additional workloads for instructors who are willing to commit to the online environment. Any tool that can ease the creation process is a welcome addition to even the most technologically savvy professor.

Bethune-Cookman College is a historically black college located in Daytona Beach, Florida. The student population contains a large number of students who lack a strong quantitative background. Statistics is an especially difficult course for these students. The difficulty of the course material is coupled with the perception by business students that statistics is extraneous to their career goals. Statistics students tend to lose focus and interest in the coursework. The challenge to the instructor is to provide the students with a concrete frame of reference that will inspire and corral their interest in the course material and facilitate the learning of the material.

The ability to use spreadsheet programs, in business related scenarios, is an important skill for all business majors. Spreadsheet exposure, creation, and function need to be reinforced throughout the business student's college career. Historically, spreadsheets have been used regularly in the Mathematics and related quantitative subjects' classroom, as a tool for helping students understand mathematical concepts, for a long time (Ozgun, 2002). "Relationships among different types of representational models such as tables, equations, and graphs are more easily comprehendible when all representations are visible at once and linked to each other."(Ozgun, 2002). Spreadsheets fuel the students' ability "to focus on the mathematical reasoning by freeing them from the burden of calculations and algebraic manipulations" (Ozgun, 2002). Therefore it is logically to assume that use of spreadsheets should to be integrated into as many business classes as possible. Software used for statistical analysis is usually in a spreadsheet format and is therefore a good fit for technology-based spreadsheet lessons.

When using a statistical software application program, such as PHStat, the critical decision-making is an integral part of the teaching approach. By using actual or realistic data, we can teach students to look beyond the role 
of statistical analysis and to make the leap to being able to successfully interpret statistical data in a managerial context. The use of more realistic databases can greatly improve business student's decision-making skills and thus better prepare students for the business world. In order to prepare students for employment, knowledge transfer is critical and can be achieved by teaching a subject matter with emphasis on real world applications (Lambercht, 1993, 1997).

The tremendous growth of information technology has created a need for workers who can manage and manipulate vast amounts of data. Educators are often criticized for training students using unrealistic and ill structured problems (Brown, Collins \& Duguid, 1989; Sternberg, 1985). Abramovich's and Nabors'(1997) conclusions showing how using spreadsheets helped seventh grade algebra students develop problem-solving skills can be applied to college students as well. Findings show that liberal use of on-line lessons reinforces learning activities for a diverse population (Drago, 2004).

The Professor's challenge, when adding additional technological interface to the classroom curriculum mix, is not to make the learning tool more difficult than the statistics problem or the learning objective. Students often lack broad based computer skills. Professors often lack the time to teach computer software specifics. Any time an educator must teach a computer application such as PHStat or Excel, they must deviate from the required course curriculum. The conundrum of many business professors is how to integrate a computer application program into a classroom activity without losing precious teaching time. Even schools that have the resources to provide a full support computer lab may not be able to assist a student with a specific software package like PHStat. (PHStat is Prentice Hall's statistical add-in system. It enhances Microsoft Excel and facilitates computer based Statistics lessons.) While help may be available for Excel, Word and the Microsoft family of applications, guidance on specific programs relating to business, math, science and statistics would require an expertise beyond what a college computer lab assistant might have. Inadequate guidance by the college technology support team will only frustrate the student more and this will lead to even more resistance to the learning activity that requires the use of the specific application package.

\section{ENTER CAMTASIA}

Camtasia is a full service capture program that can be used to record, edit and publish training demos and presentations in a variety of common video formats. It is available at http://www.techsmith.com. By using a capture program such as Camtasia, the professor can prepare video based lessons with sound overlap that show in great detail how to use a specific program in the context of a specific course. (There are many capture programs available, however, our Bethune-Cookman College technology group has selected Camtasia for this purpose.) The resulting video lesson can be uploaded to a Web Page or Course management application such as Blackboard or WebCt. These, in turn, provide the student with continuous access to the lesson for review purposes.

\section{DEMONSTRATION PROBLEM}

Students are presented with the following problem: The director of a large college of business would like to be able to predict grade point index (GPI) based on Graduate Management Aptitude Test (GMAT) score. A sample of 20 students who have completed 2 years in the program is selected. Students are required to interpret the meaning of the slope (b1) and the y-intercept.

\section{Demo Example (Sans Professor's Voice)}

The Demonstration Lesson is a step-by-step video presentation with the professor's voice guiding the student through that use of the PHStat application program. A series of spreadsheets are shown which solve the demonstration problem. The evolution of the solution from beginning to end is shown in video format. The results are explained step by step by pointing and clicking on relevant segments of the output with voice narration. The use of a capture program turns a single classroom activity into a dynamic research tool that can be referred to throughout the semester.

Exhibit 1, Exhibit 2, Exhibit 3 are still shot examples of the video presentation. 


\section{Exhibit 1}

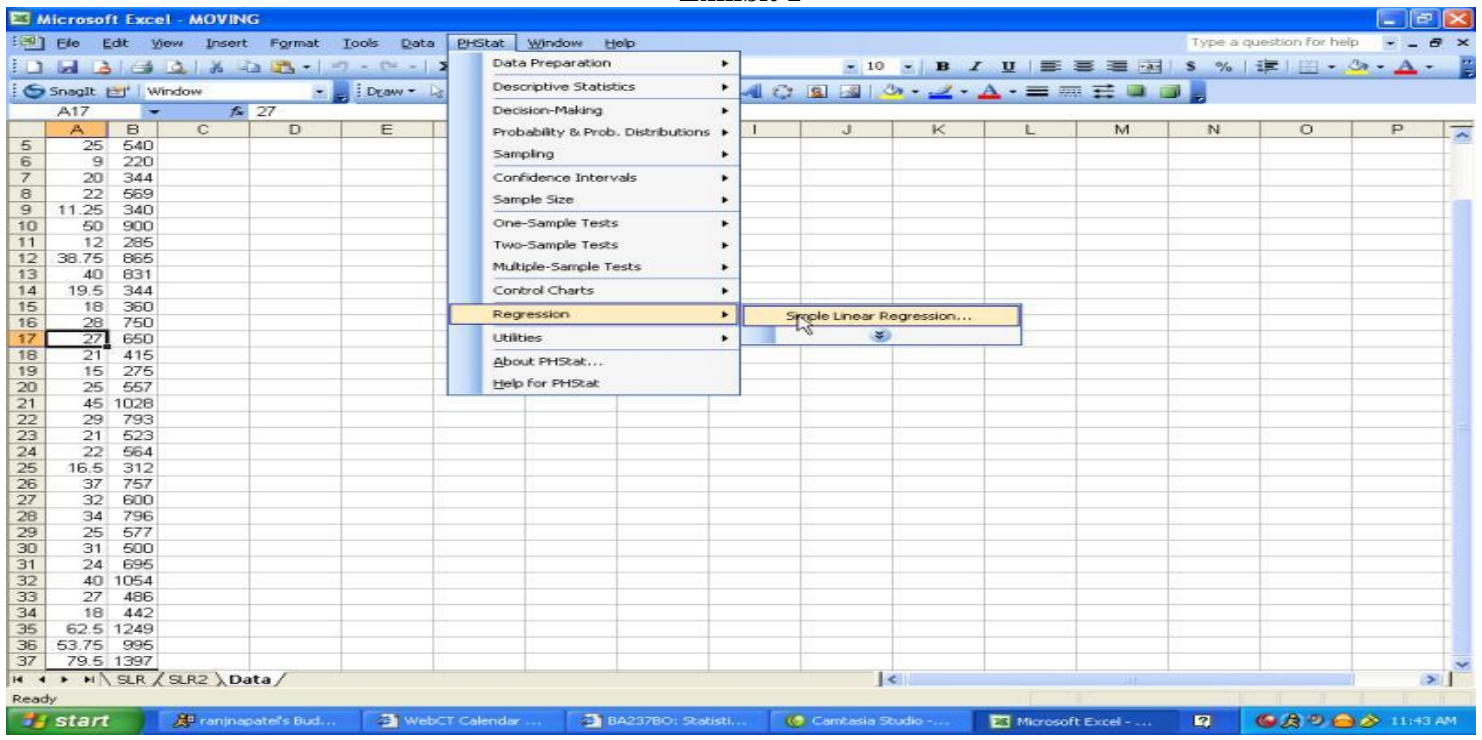

Exhibit 2

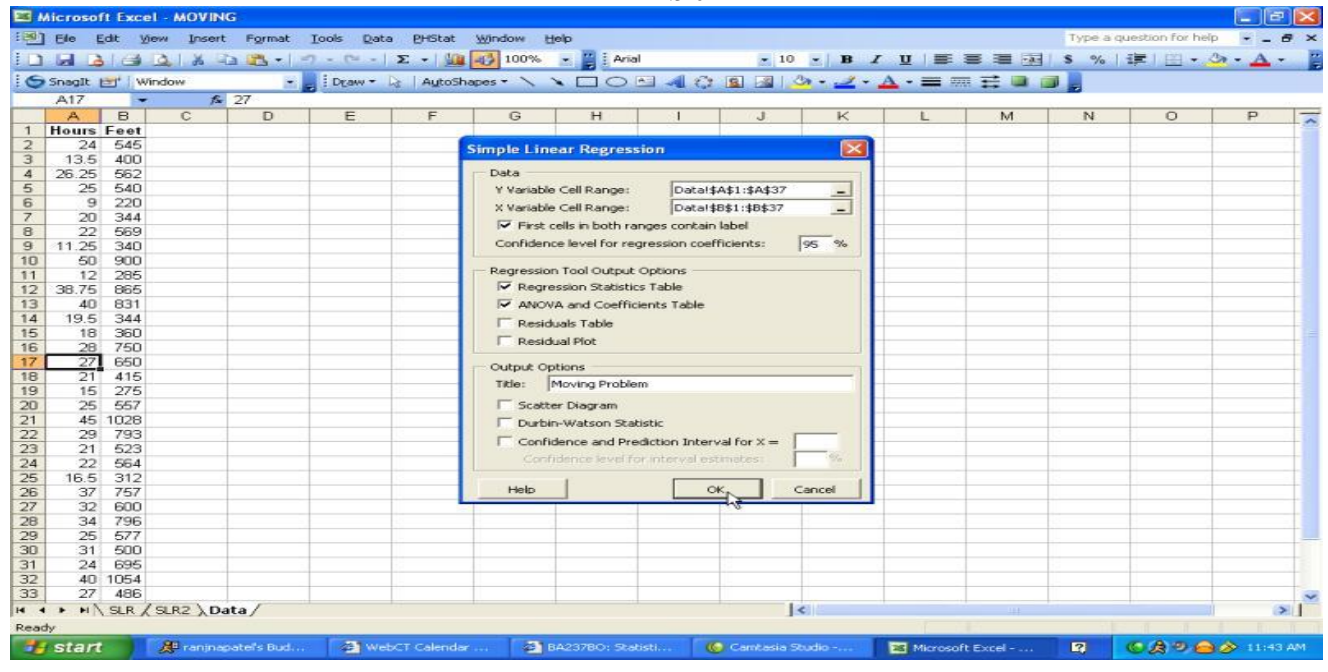

Exhibit 3

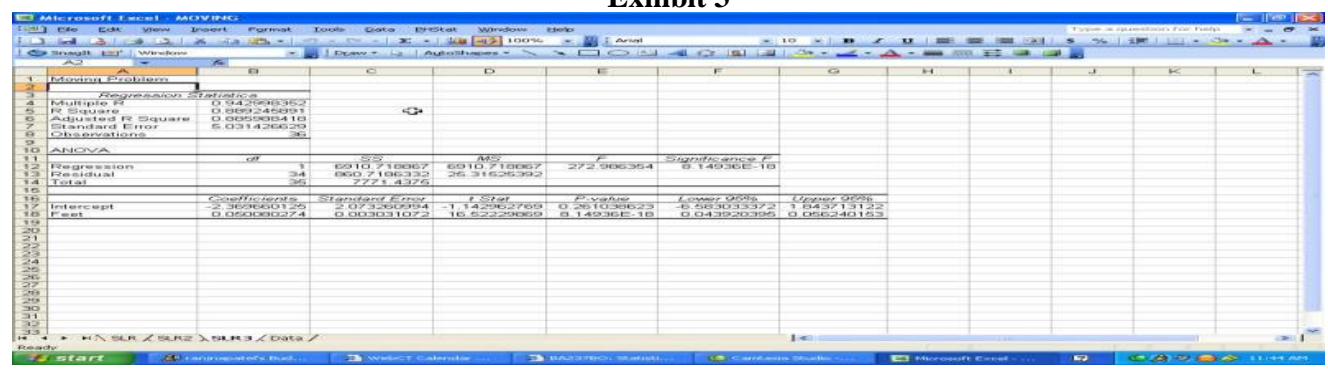




\section{CONCLUSION}

Bethune-Cookman College students who master the use of PHStat in statistics go on to use it in the required upper level Research Methods course. This course requires student to select a topic, create a hypothesis, survey, or examine, a sample of a population, review literature relating to the area of study and write a paper that includes statistical analysis and conclusions. The Demonstration lesson created in the Statistics class is available for reference online long after a student passes through the statistics classroom.

The use of Video/Sound Capture programs allow the professor to provide a clear reusable illustration that can be referred to and followed by the student whenever the student is required to use the particular spreadsheet applications in solving statistical problems. The video is available via WebCt or faculty web page to students at all times.

Table 1 shows the results of a student survey that was administered at the end of the Fall 2003 Statistics course, where the video captured problem was not used, and, the Fall 2004 Statistics course where the video captured problem was available for student reference.

Table 1: Comparison of Students' Responses to Selected Questions-Fall 2003 and 2004

\begin{tabular}{|l|c|c|}
\hline & $\begin{array}{c}\text { Fall 2003 } \\
\text { Video capture } \\
\text { demonstration not available } \\
\text { for use }\end{array}$ & $\begin{array}{c}\text { Fall 2004 } \\
\text { Video capture } \\
\text { demonstration available for } \\
\text { use }\end{array}$ \\
\hline Students using spreadsheet applications & $35 \%$ & $65 \%$ \\
\hline Performance on interpretation of test results questions on exams & $45 \%$ & $73 \%$ \\
\hline Use of realistic data sets (in other courses) & $10 \%$ & $44 \%$ \\
\hline $\begin{array}{l}\text { Students feeling statistics as an important skill for successful } \\
\text { business careers }\end{array}$ & $30 \%$ & $72 \%$ \\
\hline Students who say they enjoyed statistics & $20 \%$ & $46 \%$ \\
\hline
\end{tabular}

Table 1 shows the dramatic effect that an online video lesson can have on students. Since using the online demonstration lesson more Bethune-Cookman College Business students are using spreadsheet applications in later classes. Statistics students' comprehension and test results have improved with the use of video capture demonstrations. Students are able to use more realistic data sets and relate them more often to business problems. Students are able to apply statistical concepts in other business courses and they have a greater appreciation of statistics and are more likely to see statistics as an important skill necessary for a successful business career. Finally the survey shows that more students feel that the Statistics course is not only more useful but actually more enjoyable.

Many new technologies are available today that are interactive and can make it easier for the educator to create online learning environments in which student learning can be expanded and reinforced with a variety of challenging activities. Online lessons provide continuous interaction that can provide immediate feedback and continual refining of students' understanding while building new knowledge. Use of technology can help both students and faculty develop skills necessary for success in today's business world.

\section{REFERENCES}

1. Abramovich, S. and Nabors, W. (1997). Spreadsheets as generators of new meanings in middle school algebra. Computers in the Schools, 13 (1-2), 13-25.

2. Brown, J. S., Collins, A., and Duguid, P. (1989). Situated cognition and culture of learning, Educational Researcher, 18, (1), 32-42.

3. Drago, William A. and Wagner, Richard J. (2004). Vark Preferred Learning Styles and Online Educaton. Management Research News. Patrington. Vol.27, Issue 7, pg. 1. 
4. Ozgun-Koca, S. A. (2000). Using spreadsheets in mathematics education. Office of Educational Research and Improvement (ED), ERIC Accession No. ED463951.

5. Lambrecht, J. J. (1993). Application software as cognitive enhancers, Journal of Research of Computing in Education 25 (4), 506-520.

6. Lambrecht, J. J. (1997). Teaching problem solving of employment preparation, Journal of Business and Training Education 6 (Spring), 17-49.

7. Mayor, Tracy (2001). E-learning: Does it make the grade? CIO. Framingham. Vol.14, Issue 7, pg. 132.

8. Sternberg, E. R. (1985). Teaching critical thinking: Are we making critical mistakes? Phi Delta Kappen, 67 (3), 194-198.

\section{NOTES}




\section{NOTES}

